\title{
A Sediment Budget for the Queensland Murray Darling Basin
}

\author{
$\underline{\text { W Davidson }}^{1}$ \\ ${ }^{1}$ Queensland Department of Natural Resources and Mines \\ Email: Wes.Davidson@ehp.qld.gov.au
}

\begin{abstract}
Source Catchments Water Quality models were developed for the Queensland section of the Murray Darling Basin. The Queensland Murray Darling Basin (QMDB) Water Quality Models were built to assist in the development of water quality guidelines for Murray Darling Basin planning requirements. Total Suspended Sediment (TSS), Total Nitrogen (TN) and Total Phosphorus (TP) were the constituents of interest.

This work built on the experience of the Great Barrier Reef (GBR) Paddock to Reef modelling program and applied a similar modelling approach. Three separate models were created for the QMDB: South West catchments Bulloo, Paroo, Warrego and Nebine catchments (SWNRM), Condamine, Balonne and Maranoa catchments (CBM) and Border Rivers and Moonie catchments (BRM). Models were calibrated using the Sacramento rainfall runoff model coupled to the parameter estimation software (PEST). Due to the limited water quality monitoring data available across the region for calibration, historical water quality (WQ) data was correlated against log transformed flow to build a relationship between TSS, TP and TN and gauge discharge by catchment. The resulting concentration values were used to calculate daily through to average annual loads. These loads were then used to assist with model calibration.
\end{abstract}

The hydrological calibration achieved a percent bias (PBIAS) of less than 5\% for 36 of the 37 gauges used for calibration. Modelled average annual TSS loads were estimated to be 1,906 kt/yr for the SWNRM catchments, $198 \mathrm{kt} / \mathrm{yr}$ for CBM and $53 \mathrm{kt} / \mathrm{yr}$ for the BRM catchments for the 35 year climate period (1980-2015). In terms of the overall QMDB sediment budget, gully erosion contributed 43\%, streambank $37 \%$ and hillslope erosion $20 \%$ of the total sediment load exported. Limited measured data was available across the full range of flow heights for water quality calibration which meant that there is a degree of uncertainty about the measured estimates used to validate the model, a common problem worldwide.

This model has been used in the development of high and low flow water quality guidelines for Water Quality Objectives for the Qld Environmental Protection Policy. The model has the potential to be used and refined by regional NRM bodies in future years to prioritise natural resource investment in improved land management practices. Using a model in a data poor area has highlighted the value of event monitoring data collection to calibrate and validate water quality models. Development of such a model incorporating a range of erosion processes provided a basis for prioritising future research in catchments, in particular improve our understanding of sediment transport where limited measured data is available.

Keywords: $\quad$ Water quality, Source Catchments, Queensland Murray Darling Basin 


\section{INTRODUCTION}

The QMBD Water Quality Modelling project was funded by Murray Darling Basin Authority (MDBA) working with the Queensland Environment and Heritage Protection Department (Qld EHP) and Queensland Department of Natural Resources and Mines (Qld DRNM). The guideline development and modelling form the basis of Queensland's input into both the Murray Darling Basin Plan (Water Quality Management Plan) under the Australian Water Act 2007 and the Healthy Water Management Plans which provide Water Quality Objectives (WQOs) under the Environmental Protection (Water) Policy 2009.

Ideally, water quality guideline development would draw heavily on available water quality data as opposed to modelling. Over the past 30 years in the QMDB catchments, water quality data has been collected sporadically and often not sampled throughout the entire hydrograph. Isolated projects for targeted event sampling have provided a very limited event sampling data set (Waters, 2008).

Therefore, in such a data poor environment, modelling is being used in the first instance to compliment an event monitoring program and fill the gaps across such a large area as a first approximation.

The Source model development builds on the learnings and experience of the Great Barrier Reef, Paddock to Reef modelling program(Waters, 2014) and previous modelling work in the region (Waters, 2008). A similar modelling approach was adopted in this project for consistency. Recommendations from Waters (2008) included the of the need for greater WQ reference data at a range of flows, and the need to identify sediment sources into hillslope, gully and streambank erosion, both of which have been included in this project. This paper will outline how the model was developed and calibrated in a data poor environment to provide catchment wide sediment and nutrient load estimates for the Queensland section of the Murray Darling Basin.

\section{STUDY AREA}

The total modelled area drains 336,000 $\mathrm{km}^{2}$ of Queensland (Figure 1), west and south of the Great Dividing Range into New South Wales. The catchment has highly variable annual rainfall ranging from 1,250 $\mathrm{mm}$ in the east to less than $500 \mathrm{~mm}$ in the west. Annual evaporation ranges from $1,600 \mathrm{~mm}$ in the east to $2,800 \mathrm{~mm}$ in the west. The dominant land use for all catchments was grazing, which ranged from $65 \%$ of the eastern catchments to $95 \%$ of the western catchments.

Due to potential impact on run time given the large area to model, the region was grouped into three separate models based on land use and climatic factors. The three separate models were created for the Border Rivers and Moonie (BRM), Condamine, Balonne and Maranoa (CBM) and Paroo, Warrego, Nebine and Bulloo forming SWNRM catchments (Figure 1).

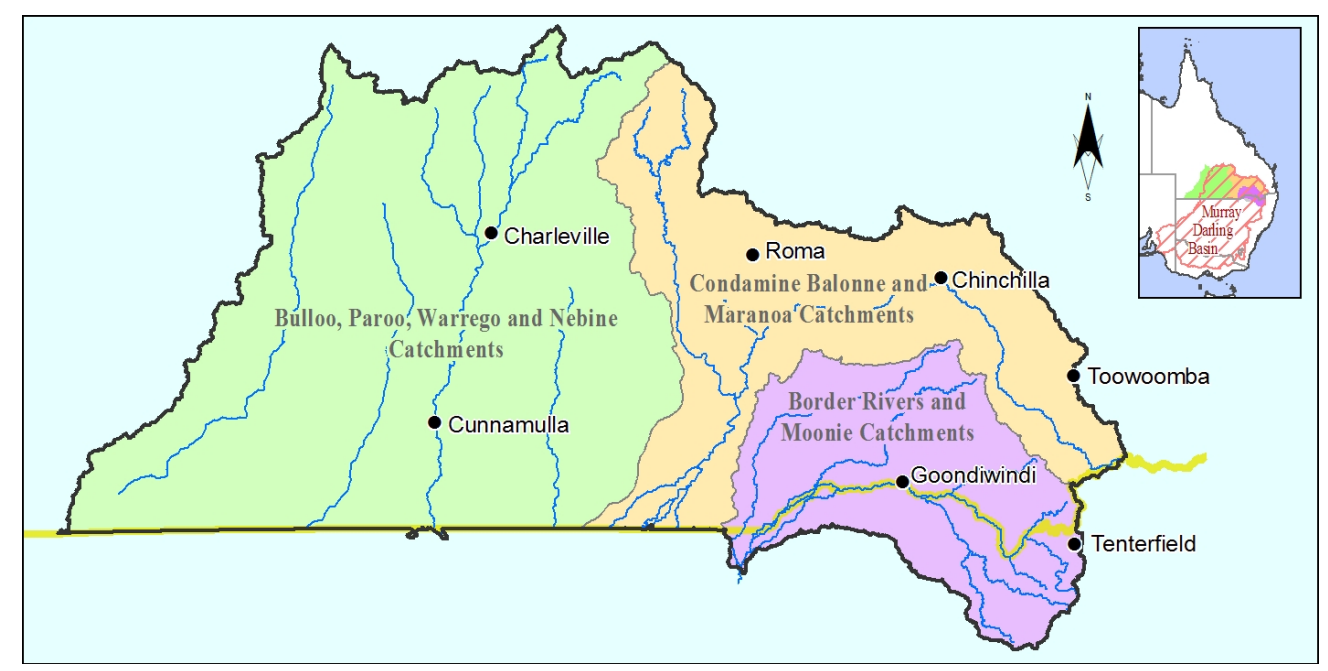

Figure 1. Qld Murray Darling Basin Model Study Area and the different shading indicating the spatial extent of the three Source models. 


\section{METHODOLOGY}

The methodology was based on the approach used by the Great Barrier Reef Paddock to Reef modelling program (Waters et al, 2014) using a modified eWater Source platform, including the hydrological set up of rainfall runoff, climatic variables and functional units (FUs) based on land use. The approach attempts to separate hillslope, streambank and gully erosion processes. . Where possible, the same state wide input data layers were used as per the Paddock to Reef modelling program to parameterise the constituent models.

\subsection{Hydrology}

The calibration process was developed building on previous calibration work in the GBR (Ellis, Doherty \& Searle 2009). Hydrology calibration was undertaken using PEST, a model-independent parameter estimation tool (Doherty 2009). The Sacramento rainfall runoff generation model was used as it provided improved runoff predictions over the previously applied Simhyd (Zhang, Waters \& Ellis 2013). Storage dynamics (dams/weirs) were simulated, as well as irrigation extractions, channel losses and inflows such as sewage treatment plant discharges, through specific node models. A 35 year climate simulation period was chosen (1/1/1980 $31 / 12 / 2015)$. This period included a range of extreme wet and dry periods which is an important consideration for hydrology calibration. Daily climate input files generated for each sub-catchment were used to calculate daily runoff. Rainfall and PET inputs were derived from the Department of Science Information Technology Innovation (DSITI) Silo Data Drill database (Queensland Government 2014).

Landuses/FUs that were deemed to have similar hydrologic response characteristics were grouped into two broad 'hydrologic response units' (HRUs); namely timbered or 'forested' areas, and 'non-forested' areas. These broad groupings were selected from previous research in Queensland which suggested these land uses have measurably different drainage and runoff rates given the same climate and soils (Thornton et al. 2007).

Flow data was extracted from DNRM's Hydstra Surface Water Database to provide the 'observed' flow values for calibration. After flow calibration, the parameter sets were applied to each subcatchment upstream of each calibration gauge and the most appropriate nearest neighbour parameter set was applied to the ungauged areas.

Once calibration was completed, model performance was assessed for the 38 gauges used in the calibration process. The model performance was assessed against observed flow data using the criteria recommended by Moriasi (2015) including assessment of flow bias (PBAS), monthly Nash Sutcliffe Efficiency (NSE), coefficient of determination $\left(\mathrm{R}^{2}\right)$ and ratio of the root mean square error to the standard deviation of measured data (RSR).

\subsection{Constituents Model}

The water quality constituents modelled were TSS, TP and TN. The constituents were modelled using the Dynamic SedNet plugin (Ellis 2017) created for the eWater Source platform. The Dynamic SedNet modelling functionality provides the ability to estimate gully and streambank erosion and floodplain deposition. The RULSE model (Renard et al. 1997) was used to model hillslope erosion for cover dependent land uses (e.g. grazing, conservation and forestry) and EMC/DWC models were used for the remaining minor contributing land uses (urban, horticulture and the 'other' land use categories). For detailed methodology refer to Waters et al. (2014).

A range of spatial and point based data sets were required to parametrise the gully and streambank models. The gully model required a gully density map as an input to spatially identify where gully erosion occurred in catchments and to estimate their associated density. As no gully density map existed for the study area, a map was developed using the methodology set out by

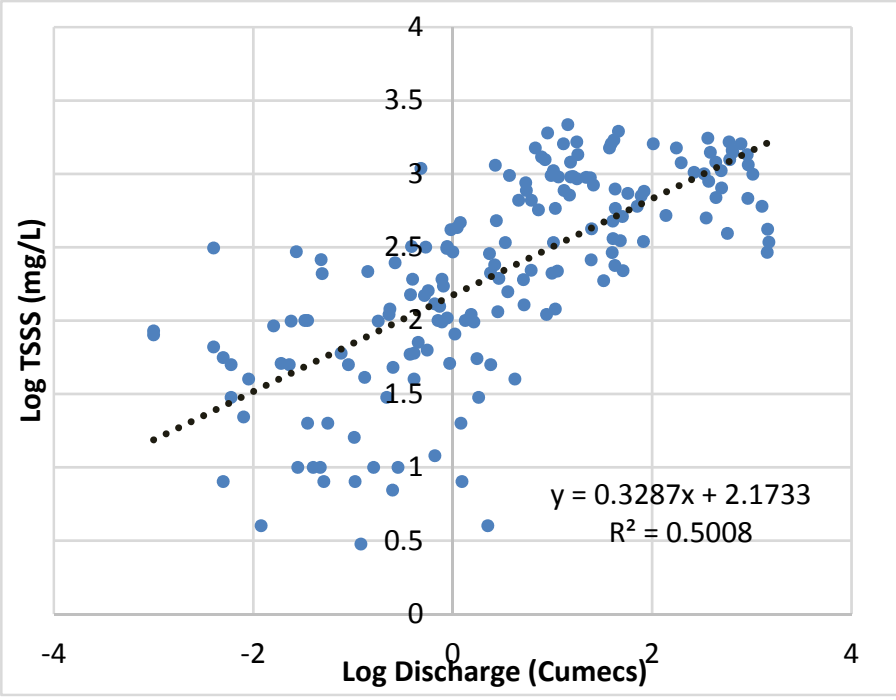

Figure 2. Log Discharge and Log TSS relationship for SWNRM Darr et al. (2014). Sixty sample areas $\left(10 \mathrm{~km}^{2}\right)$ were mapped throughout the QMBD. A relationship between 
gully density, cover and land type was then used to extrapolate the gully density to cover the entire study area. The map was then validated by an expert panel.

\subsection{Sediment Load Calibration}

Historical TSS, TN and TP WQ data from Qld and NSW were collated across for gauging stations where there was a known discharge level for the site and time of WQ data collection. The water quality data was then log transformed and correlated against log transformed flow by catchment to provide the basis for a relationship between flow and constituents (Figure 2 is a SWNRM example). Three separate regression relationships between TSS and discharge were created for each model area based on the data available within the catchment.

The concentrations were correlated to hourly flow and the resulting regression equation was used to provide daily, yearly and average annual loads at 13 gauging stations used for calibration. This regression based load became the "observed" or reference data used to calibrate the model against. Load calibration was undertaken through an iterative process of modifying parameters (such as delivery ratio and gully cross section) within the Dynamic SedNet plugins for Source Catchment minimising the difference between modelled annual predicted load and the "observed" annual loads.

Table 1. Hydrology and TSS Load Performance Evaluation Criteria and Results

\section{RESULTS}

\subsection{Hydrology Calibration Result}

The model evaluation criteria as set out by Moriasi et al (2015) outlines the following evaluation criteria for model performance for monthly flow which describes "Very Good" as Nash Sutcliffe efficiency NSE $>0.85$ and PBIAS $< \pm 5$, "Good" as NSE 0.75-0.85 and PBIAS $\pm 5- \pm 10$, and "Satisfactory" as NSE 0.6-0.75 and PBIAS $\pm 10- \pm 15$. The CBM had the best calibrations statistics which scored "Very Good" for $100 \%$ of criteria, followed by SWRNM which had $85 \%$ overall and BRM with $78 \%$ of all criteria being "Very good" (). This demonstrates that the calibration process using PEST for the Sacramento parameters was successful and calibrated to a high standard. The good

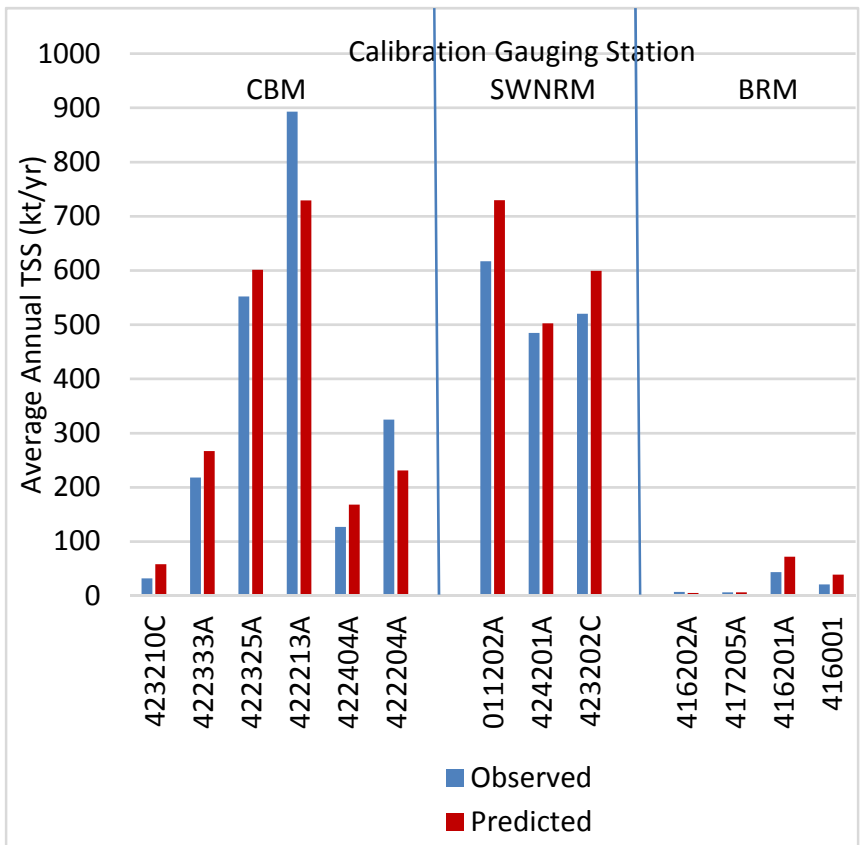

Figure 3. Average Annual Generation Predicted and Observed Loads

\begin{tabular}{|c|c|c|c|c|}
\hline \multirow[b]{2}{*}{ Hydrology } & \multicolumn{4}{|c|}{$\begin{array}{l}\text { Proportion Calibration Gauges of } \\
\text { Performance Evaluation Criteria that } \\
\text { meet Moriasi (2017) "Very Good" } \\
\text { Requirements }\end{array}$} \\
\hline & 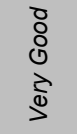 & $\begin{array}{l}8 \\
8 \\
0\end{array}$ & $\frac{7}{0}$ & 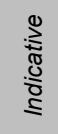 \\
\hline SWNRM & $84 \%$ & $8 \%$ & $8 \%$ & - \\
\hline CBM & $100 \%$ & - & - & - \\
\hline BRM & $70 \%$ & $21 \%$ & $9 \%$ & - \\
\hline Total & $85 \%$ & $9 \%$ & $6 \%$ & - \\
\hline $\begin{array}{l}\text { Sediment } \\
\text { Load } \\
\text { (TSS) }\end{array}$ & 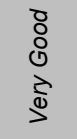 & $\begin{array}{l}\text { రి } \\
\text { ర }\end{array}$ & 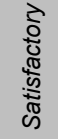 & 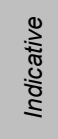 \\
\hline SWNRM & $25 \%$ & $33 \%$ & $42 \%$ & - \\
\hline CB & $4 \%$ & $29 \%$ & $33 \%$ & $33 \%$ \\
\hline BRM & $6 \%$ & $19 \%$ & $13 \%$ & $63 \%$ \\
\hline Total & $10 \%$ & $27 \%$ & $29 \%$ & $35 \%$ \\
\hline
\end{tabular}

performance results for hydrological calibration provides a solid basis for use to model water quality.

\subsection{Load Calibration Result}

Load calibration performance of each model was assessed using the model evaluation guidelines outlined in Moriasi et al. (2015), which describes "Very Good" as NSE >0.8 and PBIAS $< \pm 10$, "Good" as NSE 0.7-0.8 and PBIAS $\pm 10- \pm 15$, and "Satisfactory" as NSE 0.45-0.7 and PBIAS $\pm 15- \pm 20$. Overall the TSS calibration had lower proportion of Very High scores with most performance measures achieving "Good" and "Satisfactory" results. In SWNRM all calibration statistics were Satisfactory or better, in CBM $\sim 66 \%$ were Satisfactory or better and in BRM only $37 \%$ were Satisfactory or better. Overall, for all models, 10\% scored Very Good and 65\% 
scored above Satisfactory of performance measures for TSS ().

\subsection{Average Annual Total Suspend Solids Results}

Modelled average annual TSS loads exported for each region were estimated to be $198 \mathrm{kt} / \mathrm{yr}$ for CBM, 1,906 $\mathrm{kt} / \mathrm{yr}$ for the SWNRM catchments and $53 \mathrm{kt} / \mathrm{yr}$ for the BRM catchments.

Figure 3 shows the average annual observed and predicted TSS loads for each calibration gauging stations in the three models. The graph indicates that the model predicted loads provide a good estimate of the observed loads with both CBM (5 out of 6), BRM (2 out of 4) and SWNRM (all) having predicted loads within $20 \%$ of observed loads.

\subsection{Catchment Loads Results}

The Balonne catchment has the highest TSS generation rate at $3.7 \mathrm{t} / \mathrm{ha}$ and the Moonie has the lowest generation rate for TSS at $0.3 \mathrm{t} / \mathrm{ha}$. Of the SWNRM catchments, the highest generation for TSS occurs in the Warrego. This demonstrates there is a relatively consistent generation rate between catchments with comparable land use and climatic conditions.

Figure shows the total generated sediment load for all QMDB catchments separated into the various sources. Gully erosion (42\%) contributes the greatest percentage of the sediment load followed by streambank (37\%) and then hillslope erosion (18\%).

\subsection{Independent Validation Data}

A number of samples were collected over the past two years to compliment the modelling to be used for validation. Lab samples were taken monthly and during events on a more frequent occurrence to ensure samples were collected over the full range of the hydrograph. These samples provide an independent data set to validate the model. Figure show these independent samples plotted against modelled concentration for one site, Mungindi (416001). This result is very encouraging showing that the modelled concentration track the independent samples well over several months.

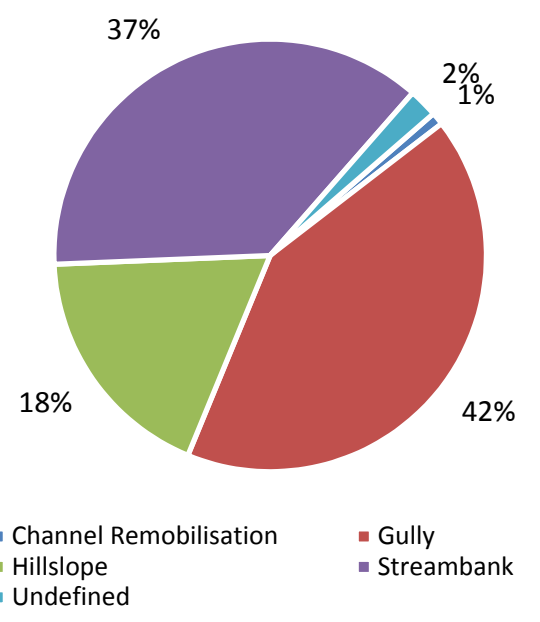

Figure 4. Generation Sediment Budget

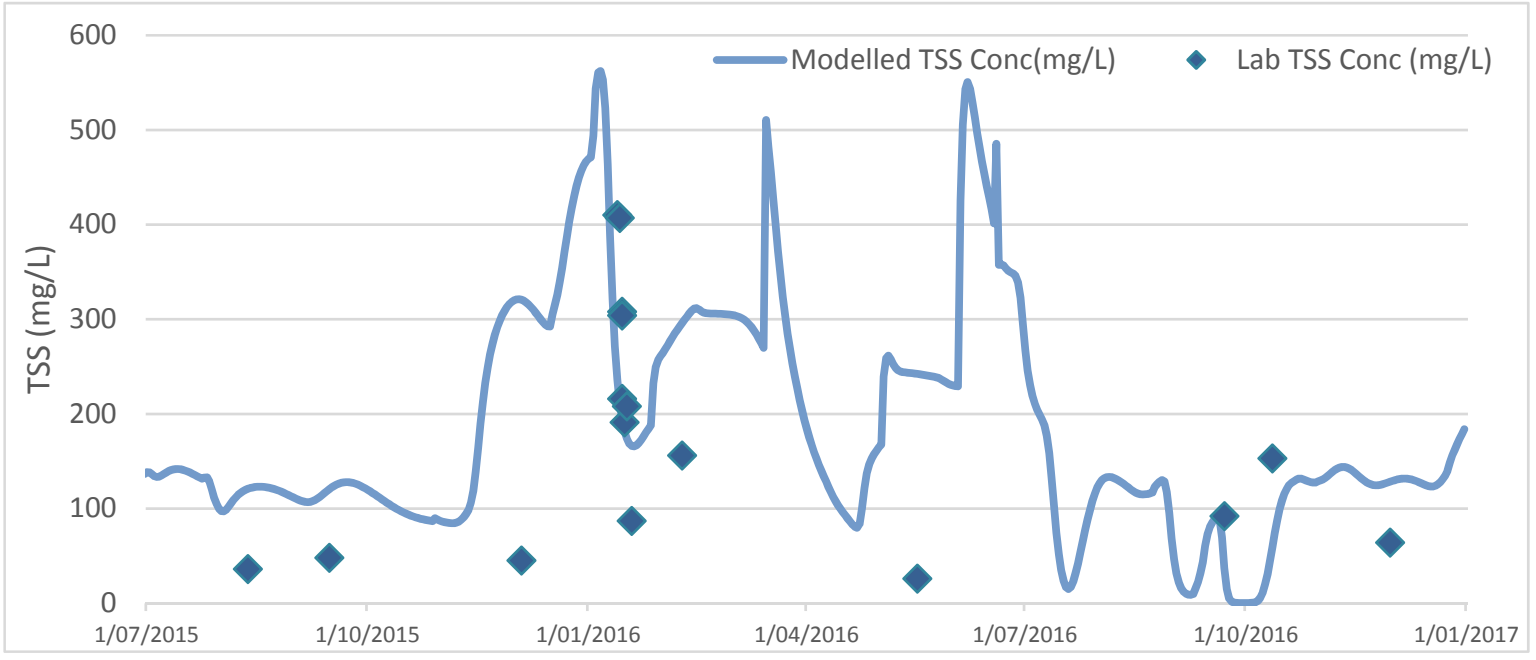

Figure 5. Independent TSS concentrations plotted against Modelled concentrations 


\section{DISCUSSION}

The Source framework provides a flexible modelling environment to estimate catchment water quality loads. The ability to develop a total landscape pollutant budget at a fine time scale is a powerful tool upon which to develop an agreed understanding of landscape dynamics.

The hydrology calibration approach using a proven method coupling PEST with Source produced a high quality calibration when assessed against Moriasi (2015) performance criteria with 36 of the 37 gauges calibrated within $\pm 5 \%$ of observed flow. The hydrology calibration was a significant improvement on the models previously created by Waters (2008).

Having limited water quality data to calibrate a model for such a large area was challenging although not an uncommon problem in the water quality area. Calibration of the model therefore required a relationship to be derived between the available sample data and flow, used to build a long-term average annual load estimate. The derived loads provided a useful reference dataset to calibrate against. However, a low number of samples for high flow events introduces possible errors in the relationship. Collecting further samples over the range of the hydrograph may result in stronger relationships. Overall, the Log-Log relationships provided a satisfactory method to calculate an "observed" set of constituent loads. This was used to compare the predicted loads to and provided a satisfactory calibration in areas where there is limited reference data to calibrate loads against. This however does not preclude a complete set of reference water quality data to calibrate against when one is available. Comparing modelled concentrations to the independent samples (Figure), was very encouraging and suggests that the model is doing an adequate job of load prediction temporally as a first approximation.

Similar contribution rates for gully, streambank and hillslope erosion were found in the Fitzroy basin (McCloskey, 2017). The Fitzroy was used for comparison due to its relative similar range of land uses, climate and size as the QMDB catchment. Fitzroy's sediment loads were 52\% from gully, 29\% from hillslope and $19 \%$ from streambank erosion, with the QMBD relative contributions of $42 \%$ from gully, $39 \%$ from streambank and $18 \%$ from hillslope.

One observation from the modelled load estimates is the contrasting loads exported for each of the basins. The difference between in generation rates of sediment between relatively similar areas of CBM (3.5 t/ha) and $\operatorname{BDM}(0.3 \mathrm{t} / \mathrm{ha})$ with both having similar climatic conditions and landuses may be explained by the differences in runoff between the two regions and secondly the low TSS concentrations of samples collected in the BDM. The runoff from the upland areas of the Border Rivers make up around $40 \%$ of the BM catchment, while the majority of the CBM is flat with close connectivity to the river under cropping. The total flow from BRM $(600,000 \mathrm{ML} / \mathrm{yr})$ is relatively cleaner due to the more natural environments in these uplands areas versus $1,400,000(\mathrm{ML} / \mathrm{y})$ from CBM covering greater areas of agricultural and grazing activity. Further water quality data gathered across the entire hydrograph will enhance the ability of building relationships to validate model predictions against.

Representing braided stream networks such as that found in the low lying areas of Warrego, Balonne, Border Rivers and the Condamine catchments, created some challenges for routing of pollutants in the current Source configuration. Losses and inflows were included at a number of locations artificially in the model to maintain a mass balance. In future modelling, an alternative approach such as aggregation of these areas into a single catchment may result in an easier model build and less complexity in constituent load calculation.

\section{CONCLUSIONS}

This model provides a consistent spatial coverage of water quality load estimates for the QMDB. This model provides improved estimates of sediment and nutrient loads compared to the previous model estimates using updated calibration methods. The method described in this paper provides an alternative method to build a calibrated constituent model in areas where there is limited water quality data sources through the creation of relationships between discharge and constituent. This method provides a way forward to model sediment loads in data poor catchments. With further refinement and additional data collection the model can be used or targeting of research priorities. 
Davidson, A Sediment Budget for the Queensland Murray Darling Basin

\section{REFERENCES}

Darr S., D. Tindall, J. Ross, B. Stone, B. Marchand (2014). Guidelines for catchment scale gully erosion mapping in Queensland: Principles, procedures and definitions. Unpublished report.

Doherty, J (2005). PEST: Model-Independent Parameter Estimation, User Manual, (5th edition), Watermark Numerical Computing, Brisbane.

Ellis, R. (2017). Dynamic SedNet Component Model Reference Guide: Update 2017, Concepts and algorithms used in Source Catchments customisation plugin for Great Barrier Reef catchment modelling, Department of Science, Information Technology and Innovation, Bundaberg, Queensland.

Ellis, R., Doherty, J and Searle, R. (2009). Applying parameter estimation and prediction uncertainty analysis to WaterCAST water quality models, 18th World IMACS Congress and MODSIM09 International Congress on Modelling and Simulation: Interfacing Modelling and Simulation with Mathematical and Computational Sciences, eds. R.S. Anderssen, R.D. Braddock \& L.T.H. Newham, Modelling and Simulation Society of Australia and New Zealand and International Association for Mathematics, Cairns, July 2009.

Moriasi, D. N., Gitau, M. W., Pai, N., Daggupati, P. (2015). Hydrologic and Water Quality Models: Performance Measures and Evaluation Criteria, Natural Resources \& Environmental Systems Community of $A S A B E$, Vol. 58(6): 1763-1785

McCloskey, G.L., Waters. D., Baheerathan, R., Darr, S., Dougall, C., Ellis, R., Fentie, B., Hateley, L. (2017). Modelling pollutant load changes due to improved management practices in the Great Barrier Reef catchments: updated methodology and results - Technical Report for Reef Report Cards 2015, Queensland Department of Natural Resources and Mines, Brisbane, Queensland

Renard, KG, Foster, GA, Weiss, DK, Mcool, DK, Yoder, DC (1997). Predicting soil erosion by water: a guide to conservation planning with the Revised Universal Soil Loss Equation, United States Department of Agriculture, Agriculture handbook no 73, 404 pp.

Silo - Queensland Department of Natural Resources. (2004). The SILO Data Drill. Department of NRM. Available from http://www.nrm.qld.gov.au/silo/datadrill/datadrill_frameset.html

Thornton, CM, Cowie, BA, Freebairn, DM, Playford, CL (2007). The Brigalow Catchment study. II. Clearing brigalow (Acacia harpophylla) for cropping or pasture increases runoff, Australian Journal of Soil Research 45 (7), 496-511.

Waters, D. (2006). Application of the EMSS water quality model for the Queensland Murray Darling catchment - Assessing the impacts of on-ground works. Technical Report of the Water Quality State-level Investment Project. Brisbane: Queensland Government - National Action Plan for Salinity and Water Quality

Waters, D. (2008). Water Quality monitoring and E2 modelling in the South West NRM region, Queensland Technical Report for South West NRM

Waters, DK, Carroll, C, Ellis, R, Hateley, L, McCloskey, GL, Packett, R, Dougall, C, Fentie (2014). Modelling reductions of pollutant loads due to improved management practices in the Great Barrier Reef catchments Whole of GBR, Technical Report, Volume 1, Queensland Department of Natural Resources and Mines, Toowoomba, Queensland (ISBN: 978-1-7423-0999).

Zhang, YQ, Chiew, FHS (2009). 'Evaluation of regionalisation methods for predicting runoff in ungauged catchments in southeast Australia', in 18th World IMACS Congress and MODSIM09 International Congress on Modelling and Simulation, RS Anderssen, RD Braddock \& LTH Newham (eds), Modelling and Simulation Society of Australia and New Zealand and International Association for Mathematics, Cairns, July 2009. 